\title{
Prospects of Nigeria Upgrading to Teacherless Classroom
}

\author{
Dr. Nsikak-Abasi Udofia \\ Faculty of Education, University of Uyo, Uyo, Nigeria \\ E-mail: nudofia@yahoo.com
}

\begin{abstract}
Countries around the world are concerned with achieving education for all by improving all educational facilities in line with international best practices. Consequently, everyone attempts to introduce technology into the classroom. Wherever technology is introduced, it dominates and replaces human and manual labour. Now that technology has been brought into the classroom the possibility is that it will comfortably replace the teacher and take over the class. This paper prepares the society for the takeover of the classroom by technology and suggests that people should prepare for it.
\end{abstract}

Keywords: Teacherless classroom; Educational technology; e-Learning; Digital classroom

DOI: $10.7176 / \mathrm{NMMC} / 93-05$

Publication date:October $30^{\text {th }} 2020$

\section{Introduction}

A classroom is where curricular interaction between the teachers and learners take place in a school. Statutorily, the class is where teachers and learners meet for teaching-learning activities. It is the site for behavioural changes, intellectual exchange and development of knowledge. Here, the teacher is in charge of facilitating classroom interaction. Hence, a classroom is traditionally where teaching learning takes place as initiated, controlled, facilitated or organized by a teacher.

In formal education, the teacher is in charge. In informal and semi-formal education, skills acquisition takes place as directed and monitored by masters. The impression created here is that, without teachers, learning cannot be conducted successfully. One wonders whether there can be learning without any teacher. However, in the later a master is in charge and learning is by observation while in the former learning is by teaching.

The usefulness of a teacher in a teaching learning environment cannot be over-emphasized. However, the latest studies have laid emphasis on the need to have teachers using instructional materials which are of technological compliance. In this technological age, the learning material is technologically oriented. The use of computer has made teaching easier and provides a wider range of possibilities for a teacher. Can these instructional materials be used to teach without a teacher? That is the question this paper seeks to address. Is there a place for a teacher-less classroom?

\section{Global Inclination towards Teacherless Classroom}

\subsection{Teacherless Universities}

In October, 2016 a university called 42, was opened in California without a single teacher employed. Characteristically, no tuition fees were required as there were no teachers to be paid. Learning was by peer to peer and the course content project based. It was practical and activity oriented. After sometimes, it was observed that the students developed greater confidence in problem solving and were more independent in their study habit. Incidentally, it encouraged cooperative learning and discouraged negative competition within their classmates. It helped in developing life-skills, creativity and problem-solving ability among the leaners. The graduates of the programme gained employment easily in industries and performed outstandingly well in their work place. Generally, they performed better than their counterparts from traditional schools when employed. The warning in this pilot study is that teachers have overstayed their welcome in the classrooms. They are just making education expensive and learners unemployable (Nick, 2014).

\subsection{Digital Classroom}

There has been an attempt to introduce the use of the digital Instructional materials like the mp3, mp4, YouTube and e-books into the classroom. With the current development and paradigm shift in digital literacy, how are we sure that these instructional packages will not become digital teachers in the future? Just like the formation of the 
internet, classroom could link together or form an educational network or the lesson is taught by one model teacher and transmitted to others while lessons will be delivered by the digital teachers (Nick, 2020). The vision is that in the future, learning will be technologically branded. That is student will be taught by online facilities. Actually, it may involve learning from online media and video technology with group work and individual study (Fletcher, 2013).

\subsection{Using social digital teacher or using social media}

Social media is the current technological perspective for making life more comfortable. As a result of the internet there is information explosion and not only that, this information is readily available to everyone. This raises the discussion of what use a teacher is when what they propose to teach could be downloaded from the internet. As learners have access to the internet, can't they learn by themselves? However, do students have the skills to evaluate, select, process, organize and translate online information into lessons? They need some form of guidance. But if this learning method is properly developed, such hindrance will swiftly become a thing of the past. In parts of the world where there are shorter supplies of teachers, online learning is inevitable; even where there is enough supply of teachers it could be used complimentarily. It should be observed here that teacherless classroom does not necessarily mean school-less society. So, if the school is behind what the student is doing, guided learning can be assured.

\subsection{Online learning/Distance learning/Open University Education}

The internet is the most explosive communication phenomena in this century (Galbreath, 1997). One of the basic beneficial uses of the internet is online learning which is derived from online communication system. The Online communication is actually an interaction between persons using the internet or other subsidiaries as medium such as the world wide web, email, video conferencing, group chat, social media, serial and various others software. In such case it does not involved person to person communication but people can interact face-to-face online (Open University Education, 2019). Kaufman (1998) predicted that the internet will be revolutionized educational system, just as the printing press did. On the other hand, distance education allows access to education to those who so desire. Distance education allows students from urban, metropolis, other nations and remote areas or those who may necessarily have no access to education to learn (Roblyer, Edwards \& Hauriluk, 1997). It allows students to learn not only with no physical teacher but in a virtual class. Online communication and distance education allowed for persons not only to learn but to share information and ideas and at the same time make learning possible through sharing of pictures, video, sound and could be very beneficial to various types of learners irrespective of age, location, vocation and gender. Phipps (1997) observed that all but one of Gardner's seven intelligences are met using distance education. Only the Kinesthetic aspect of his theory is not reached in distance education. Distance learning can benefit different types of learners without added preparation.

Interestingly, distance education is the first educational programme to have completely embraced online communication. This has caused some schools of thought to believe that distance education is the educational paradigm shift of the future. However, the negative side or side-effect of distance education is the absence of simple verbal interaction and human presence which together with textual interaction makes traditional learning interesting.

\subsection{Teacherless Campuses}

There has been a bold attempt to introduced teacherless classroom in many institutions. In Carnegie Mellon University, lecturers in introductory technology, data structures and algorithms courses use videos and share via social networking during lecture. The main objective is to accommodate more students, while maintaining instructional quality. It is known as multi-year research. The major purpose is to teach a wider diversity of student with different background at the same time with identical curricular performance objective. For instance, the project sponsored by Google is designed to be teacherless, that is, to exclude teachers in the classroom (New Google and CMUmoonshot, 2019). The courses are run by online posting of assignments and grades. Projects conducted in group are completed through collaborative software. Faculty, parents and other staff are coordinated through this education platform. According to reports, their graduate students are on high demand.

\section{Why Nigeria Will upgrade to the Teacherless Classroom}

1. Large enrolment of students: Presently there is an explosion in the school enrolment and population. The classes are overcrowded and need serious assistance to provide a learning environment. Moreover, the present infrastructure lacks the carrying capacity of the student enrolment. Neither do they have the carrying capability to cater for the demands of the number of students. What higher institutions do is to reduce the admission size, which would be totally unnecessary should virtual learning be adopted. 
2. High Pupil's Teachers Ratio: In public schools, the pupil teacher ratio is 1:55 in primary school. In the secondary school depending on courses it ranges from 1:20 to 1:500 especially teachers of compulsory subjects. Consequently, the teachers are compelled to use traditional teaching methods and work excessively in the midst of scarce resources.

3. The nature of the teaching profession: The reality is that many new teachers leave once they realize the pressures that the teaching job come with. Akinduyo, (2014) posited that Teaching can be defined as the axon moving education impulse to deliver growth, development and knowledge. To Oyekan (1994) teaching is a profession engaged in human resource development for individual and economic growth. Olatunji (1996) saw teaching as a social function that aims at necessary growth in others. However, the teaching profession is endangered as many are leaving the profession due to the condition of service. Actually, those presently in training are doing so just to get admission and go to the university. This is caused by the poor condition of service the teachers are exposed to (Oke, Ogundele, \& Mainoma, 2017). Presently there is shortage of qualified and dedicated teachers in the system. Private schools whose condition of service is poorer are employing various unqualified teachers. The solution is for greater acceptance of technology in the classroom, to fill the gap created by disgruntled and absence of teachers to attain to the educational needs of students. Certainly, teachers are being phased out of the classroom, replaced by technology but by default.

4. Inability to employ new teachers: Presently the teachers are either underpaid or overworked. It is not farfetched that they will underperform. However, the little stipends are owed in several states in the federation. In effect, it is practically impossible to employ new teachers. In effect there are vacancy or employment gaps all over the schools. Yet the government cannot employ new teachers because of supposed scarcity of funds.

5. Improper output of trained teachers: The teacher's trainers are always embarrassed by the output of teachers. In recent times, some supposedly professionally trained teachers find it difficult to pass competitive employment examinations taken along with other non-professional teacher applicants. Unfortunately, this has resulted in the trained teacher being denied employment due to their poor performance. There is therefore need for a centralized lesson for all, if professionally trained teacher are becoming more difficult to source and employ.

6. Use of video technology: The use of video technology has been tested and found more effective than the use of the traditional teaching method. The study shows that apart from improving achievement it also enhanced interest. Already, in the Nursery Schools (early childhood care education), it is the preferred teaching technique. The use of video in teaching is widely used especially in private schools. All that they do is to get a mate to assist in a guided discovery method. Communication arts, theater arts and even visual arts are making extensive use of the video technology. What is left is for school proprietors to have the confidence to extend same to all classes. If that is done the classes will become teacherless.

7. Current hype for ICT: It is certain that the use of ICT (information and communications technology) has completely taken over the application of other tools in recent times. If all form of learning is mainstreamed into ICT, it could go a long way to make learning easier. Presently, there are several educational lessons uploaded on YouTube. It is a matter of time that school teachers will use such. Already, past graduates' lecturers are using such lesson successfully in their classes.

8. New paradigm shift: If Nigeria delays in adopting the teacherless concept then when other nations would begin Nigeria will be forced to start it prematurely. Then, both the struggle to catch up and failure to do so will certainly impact negatively on various aspects of social the economic life.

9. Cost effectiveness: Teacherless classrooms would reduce the cost of education significantly. Facilities used for teachers' maintenance and welfare will be used to for teaching. Teachers' remuneration will also go off education budget. The benefit will be ploughed to develop the system.

10. Environmental phenomenon: Environmental changes can force dramatic changes in the education system. For instance the spread of the coronavirus infection in Nigeria has compelled the nation into online lesson. The Federal Government had to launch free e-learning portals for pupils and students in primary and secondary schools nationwide. This was in compliance with the medical authority recommendation for the closure of schools to prevent the spread of the novel coronavirus (Covid-19) (Adedigba , 2020; Agencies, 2020; Idoko, 2020). The Nigerian government also launched virtual learning academy and various other institutions have also gone online. Such related cases if it lasts, will result in the use of online teaching permanently. 


\section{Possible Limitations to of Teacherless Schools}

1. Transition period: It is true that the web has enough information for all learners; actually, enough current information for all learners. However, in this period of transition, the learners tend to lack the teacher's ability to make proper use of the internet. There is need for proper teacher training on students' use of the internet. Though, the more they teach the students how to use the internet, the more will other teachers be laid off.

2. The human factor in the class: The presence of a teacher in the classroom gives confidence to the students and provides the necessary discipline in a learning situation. Students are disorderly and show primitive tendency when they are left on their own. In other words, a teacherless classroom will lack the warmth, security and influence of a teacher.

3. Fear of unemployment: The unions and stakeholders see teaching as income generating to the family. They may not be comfortable with a situation that threatens to remove their source of revenue. They may even call out members for an industrial action.

4. Lack of political will: Nigeria has always been poor in policy making and implementation. They actually enact good policies but implement them poorly. Even when the country is aware that they need a technologically driven classroom they may not have the political will to go straight and work towards it.

\section{Indicators of Nigerian going Teacherless}

\subsection{Trends in computer based assessment}

The use of biometric capturing and related characteristics in the identification of individual or person is now extensively used for examination purposes, registration, ID-Card processing and others. It is also extensively used in monitoring and supervision in the school system. For instance, biometric apparatus is used to check teacher attendance at school and subsequently directs salary payment. The biometric data are self-explanatory and so do not need any human interference after installation, they just work according to the installation instruction. With the use of biometric tools, some private schools can successfully monitor teacher's class attendance and movement during official hours. It can also be used to obtain information on student behaviour while in school. This has been found to be a more efficient way to manage schools.

Presently the Joint Admissions and Matriculation Board (JAMB), which is charged with the responsibilities of administering entrance examination for Universities, Polytechnics and Colleges of Education, is fully utilising computer based tests for her Unified Tertiary Matriculation Examinations (UTME). The legal instrument establishing the board was promulgated by the Act (No. 2 of 1978) of the Federal military Government on 13th February Executive Council amended Degree No. 2 of 1978. The amendments have since been codified into Decree No. 33 of 1989 which took effect from 7th December, 1989 Decree No. 2 of 1978 (amended by Decree No. 33 of 1989) empowering JAMB to Conduct matriculation Examination for entry unto all Universities, Polytechnics and Colleges of Education. This tertiary institution entrance examinations are entirely computer based tests (CBT), an indication that the students have a measure of ICT competence that can be harnessed for online learning. Moreover, the UTME are registered for online, the examinations taken online under strict CCTV surveillance and the results are published online. Results of other examinational like the Senior School Certificate Examinations (SSCE) are also managed online. In effect the human factor is not involved totally in examination; this is a pointer to the fate of the future classroom.

Computation of student results in public and private universities and other tertiary institutions are migrated to online platforms. The instruction from National Universities Commission (NUC) is that all university results should be computerized and placed in the portal for student to access. This has been adopted by both public and private universities. It is also observed that in some public universities, general courses are taken with computers (computer based testing, CBT) or are set as multiple choice questions to allow for machine marking and scoring. This development shows that the present generation is already doing without some of the functions of the teacher. Recording of Result: From 2017 entry student results from the NUC directive should be online, in other words, by 2020 all result will be online. Base on this development, examination officer will no longer be needful in the universities system. It is certain that NUC is working on the programme to reduce teacher's involvement in examination matters and emphasis is on the use of modern technology in line with international best practices.

Interestingly, from 2016, cheating and examination malpractice are more effectively curbed by the Joint Admissions and Matriculation Board (JAMB) in Nigeria who introduced the CBT and follow it up with the use of the CCTV monitory system and since then the predictive validity of their result improved tremendously. In addition to that, it is observed that time wasting associated with a JAMB examination has reduced, hence some of the negative human influences on the result are reduced if not eliminated. In addition, it is very difficult for common 
examination malpractice techniques to be applied in their instances. It takes great sophistication, computer wizardry and technological expertise to cheat. In this case, it is certain that very soon, the Senior School Certificate Examination agencies like the West African Examinations Council (WAEC) and the National Examinations Council (NECO) will adopt it to check examination malpractice. As a follow up, the school system will adopt the CBT which means that school evaluation will be completely managed by computer.

\subsection{Trends in Computer Aided/Based Instruction and Distance Learning}

One may have envisaged a class in which the teacher will stay in the convenience of his room and with the help of video conferencing platform like Zoom or with more powerful electronic tools discoverable in the very near future. The students with laptops or if possible with interactive board or new improved videoconferencing technology, they will listen and take lectures from their lecturers. Even when with books, it is possible very soon one is envisaging a blended classroom in which with the use of video transmission technology by both the teacher and student can interact with their teachers, possibly using whatever advanced connectivity technological appliances would be in vogue. Learners of the present generation are used to the transition method using the Global System of Mobile Communications. As at present, the GSM is passing the fourth generation which is making very good use of packet data. It is therefore customary now to see students solving their assignment using the GSM technology. Knowing very well that educational systems will always move to accommodate new inventions, one can be sure that very soon the GSM will become education and education will become GSM. To put it straight, education will make complete use of the GSM.

Computer-based education (CBE) and computer-based instruction (CBI) are the broadest terms and can refer to virtually any kind of computer use in education settings. Computer assisted instruction (CAI), computer aided instruction (CAI) are narrower terms and most often refers to drill and practice, tutorial, or simulation activities. Computer managed instruction (CMI) is an instructional strategy whereby the computer is used to provide learning objectives, learning resources, record keeping, progress tracking, and assessment of leaner performance. Computer based tools and application are used to assist the teacher or school administrator in the management of the learner and instructional process. While CAI and CBL can refer to the use of computers in a classroom, they more broadly refer to a structural environment in which computers are used for teaching purposes. Computer programs allow students to work at their own pace along with direct and individualized feedback. The use of computers in the teaching and learning process is an important advancement in making the highest quality of education universally available and thus allowing each person to most fully develop their potential. Computer assistance to teacher is also widespread. The use of overhead projectors and the related software like Power Point Program is now a common feature in classes and in public presentations. For now, the projector is teacher's complement but the power point projector will eventually replace the teacher in the classroom. Presently, big churches use projectors and in some of the churches nowadays the overseer preaches to all the churches at once, this is virtually the fate of our present classroom, model teacher will teach in interconnected schools.

Nowadays it is possible to attain institution and graduate using online facilities. Actually, some universities have regular and online students and they are not differentiated after graduation. There is for instance the National Open University of Nigeria (NOUN). The National Assembly had passed a bill for an Act to amend the National Open University Act Cap No.6 LFN 1983 (Amendment) Bill 2017. In the open University, students are reached online and teaching learning occurs online and in satellite study centres. There are also others universities operating in Nigeria accredited for online courses who are producing graduates accepted in the Nigerian workforce.

Besides distance learning, ICT has also been extensively used in physical institutions for course registration and student academic data management. Presently in Nigerian universities, registration of courses is done online. This is in line with the instruction given by the Nigerian University Commissions (NUC) a supervisory body of the Nigerian university education system. The National Universities Commission (NUC) of Nigeria is a government commission promoting quality in of University education in Nigeria. The commission was established in 1962 as an advisory agency in the cabinet office. In 1974, it became a statutory body of the Federal Ministry of Education and is now a parastatal.

In addition to what obtains in Open Universities, regular institutions are increasingly utilising ICT in student assignments. Previously assignment in the school were done using hard copies of book, but this is not the case nowadays as most assignments are done with the assistance of internet facilities. It is practically possible nowadays to go through school without buying a single textbook. In other words, it is possible to search for knowledge online than use the print media. As it is now, if a teacher publishes a textbook and uploads the information to the internet and possibly make it free, the teacher may not even gain but the material will be used, this boils down to the fact that printing is fast becoming out-dated. If printing is out-dated it is sure that in the very near future students may 
no longer need exercise books in school. Rather laptops, phones, subscriber identification modules (sim), memory cards, Bluetooth and WiFi enabled devices and others will be the working materials.

There is also the proliferation of electronic libraries (e-Library). The internet and websites are packed full of information. With the help of massive searching engines like Google one can access and download resources. Moreover, information at the e-library is more current than from the conventional library. Information from the elibrary could be obtained free or after due subscription. Apart from the subscription, membership is completely free unlike the conventional library.

\subsection{Trends in Cashless Payment Solutions}

A cashless society describes an economy where financial transactions are not conducted with physical bank notes or coins but rather through the transfer of digital information usually an electronic exchange of money between the transacting parties. It is not difficult to argue that the cashless society which is currently in vogue will very soon produce a teacherless society. Actually, the cashless society had existed from the time when human society came into existence, based on trade by barter and other methods of exchange. Cashless transactions also became possible in modern time with the use of digital currencies such as bitcoin and ethereum which utilize blockchain technology. Now with the use of automated teller machines, mobile banking, i-banking, debit card, credit card, point of sales, and a host of other electronic commerce solutions, one can conduct any transaction without using physical cash.

\subsection{Trends in Videoconferencing}

Use of video conferencing has become the major technological expansion, especially as the global workplace grapples with the current corona virus (Covid-19) pandemic. Virtually all social media and interactive platforms have introduced the use of video technology. The video is an electronic system for recording, reproducing, play back, and broadcasting of moving visual media. Video was first developed for the mechanical television systems which were quickly replaced by cathode ray tube (CRT) systems which were later replaced by flat panel displays of several types. Video system has varying display resolution, aspect ratio, refresh rate, colour capabilities and other qualities. Analog and digital variants exist and can be carried on a variety of media, including radio broadcast, magnetic tape, optical disks, computer files and network streaming. Video conferencing is a technology that allows users in different locations to hold face-to-face meetings without having to move to a single location together. This technology is particularly convenient for business users in different cities or even different countries because it saves time, expense and hassle associated with business travel. Uses of video conferencing include: Holding routine meetings, negotiating business deals and interviewing job candidates. It is the closest threat to teachers in the classroom.

Most student and teachers are used to the social media and use them extensively these days. They have been used for contact, fixing of classes, project supervision etc, all of which are very successful. Some teachers are able to organize class meeting using the social media. Presently with the introduction of the interactive board, some lecturers in the universities are designing lessons using information from YouTube. It is correct to say that for now lecturing is a combination of online lecturers and offline lecturers in the class. It may be doubtful how this could work in the lower classes which require greater interaction and more sublime explanations. Inadvertently, it is not wrong to say that the early child care education classes are gradually becoming teacherlesss. It is the primary and secondary schools that use less of ICT. It is certain to say universities are getting more comfortable with class without any teacher. Student running full time programme see lectures regularly. Others only see teachers intermittently, some once during examination. Actually, attendance to classes is dwindling with students interested only in examination. This has caused some schools to peg a mandatory class attendance of $70 \%$ for all students before there are eligible for semester examinations.

\subsection{Trends in Robotics}

A robot is a machine especially one programmable by a computer - capable of carrying out a computer services of actions automatically. Robots can be controlled by an external control device or the control may be embedded within. Robots may be constructed to take on human form but most robots are machines designed to perform particular task. The word robot come from a Czech robota it was actually used in place of forced labour and denoted a humanoid character in 1920. The first commercial robot was built by George Oevol in 1954 and was named the inanimate. It was sold to General Motors in 1961 where it was used to lift pieces of hot metals from die casting machines at the inland fisher guides plant in the west Trenton Section of Ewing Township, New Jersey. It is certain that apart from replacing humans function, robot could add another dimension to any system they find 
themselves. For instance, imagine a teacher who can teach as long as the learners can withstand, a teacher who can never be late or absent, a teacher who cannot be out for some function, a teacher who cannot die or retire, in other word a teacher who can teach throughout the day and never falls sick and never sleeps and not even complains, it is what is expected of a teacher robot. Teacher robots will not ask for extra pay nor proceed on strike nor go for lunch during school hours, this is the teacher that can teach more than one subject and never get tired of doing any work.

\section{Conclusion and Recommendations}

Based on the current trend of events and what is obtained based on international best practices, it is obvious that the future of the classroom is a class without teachers that is teacherless classroom. The report so far revealed that the use of teachers in curriculum implementation has been reduced to only one thing which is teaching with various responsibilities gradually taken off teachers. Hence, it is just a matter of time before teaching or classroom will be left without teachers.

Based on the exposé provided in this paper, it is pertinent for all education stakeholders in Nigeria, especially the government, to put in place a machinery to accommodate the teacherless classroom, viz;

1. Computer accessories should made available in public schools at rate one student per-computer.

2. Computer studies should be made compulsory in all schools in the country

3. The generation of students who are to benefit from the teacherless class should be prepared on time.

4. In addition, the infrastructures especially electricity should be made available so as to keep the computer working.

5. Adequate security should be put in place; it is because without adequate security it will be difficult to manage a teacherless classroom.

6. All schools should have internet connection together with having an ICT employee to manage it.

7. In addition since the examination bodies have adopted and have complied with teacherless situation, school should follow suit and embrace computer based evaluation.

\section{References}

Adedigba , A. (2020). COVID-19: FG launches free e-learning portals for students. Available at: http://www.premiumtimesng.com/coronavirus/389775-covid-19-fg-launches-free-e-learning-portals-forstudents.html

Agencies (2020). Nigeria launches free e-learning portals for primary, secondary school students. e-learning resources. Available at: https://www.today.ng/technology/nigeria-launches-free-learning-portals -primarysecondary-school-student-294133

Akinduyo, T. E. (2014). Teaching Profession in Nigeria; Issues, Problems and Prospects. of Scientific and Research Publications, 4(11), 1 - 3.

International Journal

Engst, A. (1995). Making the internet connection, Macuser, II (5th May): 66-73, p. 68

Gabreath, J. (1997). The internet: past present, future educational technology, 37 (6), 39-45

Fletcher, K. (2013). Welcome to teacher-less classrooms. Available at htto://i.stuff.co.nz/national/8203607/welcome-to-teacher-less-classrooms

Idoko, C. - ( 2020, Apr 24,). FG launches free e-learning portals for primary, secondary school students,. Available at: https://tribuneonlineng.com/fg-launches-free-e-learning-portals-for-primary-secondary -school-students/

Kaufman, R. (1998). The internet as the ultimate technology and Panacea. Educational Technology, 38(1), 63-64.

Soulskill (2015). New Google and CMU Moonshot: the 'Teacherless Classroom'. Available at: https://m.slashdot.org/story/295915.

Nick, M. (2014). The teacher-less is not as close as you think. Nick Morrison contribution education Aug. 21, 2014 by gimp.

Open University Education (2019): The teacherless classroom pages. Infinit.net $>$ seguid $>$ Daniel teachersless.

Oke, T. I., Ogundele, M. O., \& Mainoma, H. M. (2017). Emerging Challenges in Nigerian

Teaching Profession: Way Forward. Academic Journal of Interdisciplinary Studies, 6 (1) 149 - 154 Doi:10.5901/ajis. 2017.v6n1p149

Olatunji, J.O. (1996). Professionalization of teaching in Nigeria: How realistic; Andrian Forum 9(1), 81-84. 
Oyekan, S.O. (1994). Fundamentals of education in W.Osisanwo (Ed). Education for Nigeria Certificate in Education, Ondo: Adeyemi College of Education textbook Development Board: pp 1-58

Phipps, P. (1997). Multiple intelligence in the early childhood classroom Columbus, Ohio: SRA McGraw-Hill

Roblyer, M.D. Edwards, J \& Havriluk, M. A. (1997). Intergrating educational technology into teaching Upper Saddle River, New Jersey. Prentice-Hall. 